\title{
Gestão do conhecimento relacionada à gestão estratégica através das práticas de $\mathrm{SECl}$
}

\author{
Knowledge management combined with the strategic \\ management through of the practices SECI
}

Mathias Talevi Betim ${ }^{[a]}$, João Luiz Kovaleski[ ${ }^{[b]}$, Silvia Gaia ${ }^{[c]}$

[a] Mestrando em Engenharia de Produção pelo Programa de Pós-graduação em Engenharia de Produção da Universidade Tecnológica Federal do Paraná (UTFPR) - Ponta Grossa, PR - Brasil, e-mail: pgmathiasbetim@gmail.com

[b] Doutor em Instrumentação Industrial pela Université Joseph Fourier, professor associado do Programa de Pós-graduação em Engenharia de Produção da Universidade Tecnológica Federal do Paraná (UTFPR), Ponta Grossa, PR - Brasil, e-mail: kovaleski@utfpr.edu.br

[c] Mestrando em Engenharia de Produção pelo Programa de Pós-graduação em Engenharia de Produção da Universidade Tecnológica Federal do Paraná (UTFPR) - Ponta Grossa, PR - Brasil, e-mail: gaia@utfpr.edu.br

\section{Resumo}

No contexto de competitividade em que estamos inseridos e no qual a única certeza é a incerteza e a única fonte de vantagem competitiva duradoura é o conhecimento, este trabalho se justifica devido ao grande número de estudos voltados para a gestão do conhecimento, mas ainda não foi encontrada uma investigação que tratasse da relação dessas duas variáveis: estratégia e conhecimento. 0 objetivo do artigo é realizar um levantamento sobre as práticas de gestão do conhecimento relacionadas à gestão estratégica. Trata-se de uma pesquisa aplicada quanto a sua natureza, exploratória e descritiva quanto aos seus objetivos, multicaso quanto à estratégia de abordagem do problema e bibliográfica e de levantamento com amostragem intencional quanto aos procedimentos de coleta de dados. Para esta investigação foi utilizado um questionário que possui escala Likert, na análise foi identificada a pontuação obtida por cada pergunta, o qual foi disponibilizado através do Google-docs para os participantes, e o instrumento foi construído sobre a teoria do processo SECI. Os resultados alcançados são: Existem práticas relacionadas no processo diário que advêm da gestão estratégica e existem algumas questões que podem ser melhoradas nesta relação: (i) Explicação de ideias e atividades; (ii) Acesso a informação construída pela organização; (iv) Colaboradores em registrar relatórios sobre projetos construídos; (v) Internalização do conhecimento através de estímulo da empresa para com o funcionário; (vi) Comprometimento dos funcionários com a empresa e vice-versa no que se diz respeito à valorização e reconhecimento. A partir deste estudo conclui-se que as organizações pesquisadas apontam um índice positivo, mas podem melhorar com a inserção de outras práticas destacadas no estudo, o que poderá resultar em melhores condições para que alcancem seus objetivos.

Palavras-chave: Gestão do conhecimento. Gestão estratégica. SECI-Processo. 


\begin{abstract}
Taking into consideration the competitive world which we live in, certainty is synonymous with uncertainty and the only source of competitive advantage is knowledge. There is a large number of studies related to knowledge management, but there is also a lack of research that addresses the relationship of two variables: strategy and knowledge. So this paper aims to survey practices of knowledge management related to strategic management. It is an applied research as to its nature, exploratory and descriptive as to their goals, multiples cases studies regarding the problem approach, bibliographic and survey by means of intentional sampling procedures for data collection. For this investigation a questionnaire considering Likert scale. The analysis has identified the score of each question which was made available through Google-docs for the participants. This questionnaire was built on the theory of the SECI process. The achieved results are: there are daily practices relating to the proceedings arising out of strategic management and there are some issues that can be improved as (i) Explanation of ideas and activities, (ii) Access to information built by the organization, (iv) Employees who could record reports on projects constructed, (v) Internalization of knowledge through stimulation of the employees by the company, (vi) Commitment of employees with the company and vice versa when it comes to appreciation and recognition. After this study it was possible to conclude that the surveyed organizations indicate a positive index, but they may improve by introducing some of the practices highlighted in this study so they could come to a better position in order to achieve their goals.
\end{abstract}

Keywords: Knowledge management. Strategic management. SECI-Process.

\section{Introdução}

0 grande desafio das organizações na era do conhecimento é a capacidade de gerar conhecimento, e isso se deve à grande força que ele proporciona em criar vantagem competitiva. Principalmente no momento em que a única certeza é a incerteza e a única fonte de vantagem competitiva duradoura é o conhecimento, as organizações se debatem com este desafio (NONAKA, 1991).

Quando a organização busca gerir o conhecimento que está presente no seu ambiente, como uma organização que cria, explica, divulga e o aplica para desenvolver melhores produtos e processos, sem dúvida influencia positivamente o desempenho da empresa aumentando sua competitividade.

Santos e Neto (2008) descrevem que a Gestão do Conhecimento oferece uma estrutura geral para a organização dos conteúdos estratégicos da aprendizagem. Isso pode fortalecer a capacidade de uma empresa em gerar respostas válidas aos desafios do ambiente externo em permanente estado de mudança, ampliando o portfólio de competências organizacionais, tendo em vista adaptar-se aos novos requisitos dos negócios e do ambiente tecnológico relacionado.

O uso do conhecimento nas organizações pode fortalecer a sustentabilidade da mesma, assim pode-se considerar que um estudo sobre GE (Gestão
Estratégica Organizacional) com a GC (Gestão do Conhecimento) será de grande contribuição para estimular o uso das práticas de gestão do conhecimento nas práticas geradas pela gestão estratégica.

Vários modelos de gestão vêm sendo concebidos buscando desenvolver o alinhamento da gestão do conhecimento para fortalecer a gestão estratégica. Nesses modelos encontramos ações, como adotar uma abordagem sistêmica para a gestão do conhecimento, desenvolver o seu componente estratégico, utilizar as tecnologias de informação e comunicação como recursos de infraestrutura e avaliar o desempenho das ações desenvolvidas (PEREIRA, 2003).

A gestão do conhecimento para a gestão estratégica tem por tarefa identificar, desenvolver, disseminar e atualizar o conhecimento relevante para a empresa seja por meio de processos externos ou internos às empresas. Com base no conceito de gestão do conhecimento, o presente estudo realiza uma análise in-loco em três indústrias de grande porte para detectar práticas de recursos humanos, cultura organizacional e sistemas de informação relacionados com a socialização, externalização, combinação e internalização, que são tópicos de conceitos mais detalhados da gestão do conhecimento.

A gestão do conhecimento contribui para o envolvimento de todas as pessoas dentro da organização, unificando as participações ativas e de opiniões, 
potencializando os resultados obtidos e a eficácia da empresa. Torna-se inevitável a relação de gestão do conhecimento com a gestão estratégica no cenário do setor produtivo atualmente, inevitavelmente eles se cruzam por meio de iniciativas diretas ou indiretamente dos indivíduos.

Na relação entre o objetivo proposto e o conceito estudado será possível chegar à resposta da pergunta de pesquisa: Quais práticas de gestão do conhecimento estão relacionadas ao processo das organizações advindas da gestão estratégica?

Como objetivo geral definimos levantar nas práticas operacionais advindas da gestão estratégica se há relação com as práticas de gestão do conhecimento, e este objetivo está dividido em três menores, (i) diagnosticar quais os processos advindos da gestão estratégica, (ii) combinar esses processos com o processo SECI e (iii) analisar a relação entre eles.

As principais motivações deste trabalho vêm do fato de não ter sido encontrada nenhuma pesquisa sobre o tema em questão com a amostra escolhida, e também pela importância que a gestão estratégica tem no cenário empresarial.

\section{Fundamentação teórica}

Os principais autores descreverão a seguir os fundamentos dos assuntos pertinentes à pesquisa elaborada. Entre os conceitos apresentados estarão gestão do conhecimento, criação do conhecimento, processo SECI e gestão estratégica com gestão do conhecimento. Todas as abordagens permeiam o interesse da presente pesquisa a fim de dar uma sustentação teórica.

\section{Gestão do conhecimento}

A preservação do conhecimento constitui parte importante da gestão do conhecimento, deste modo, ainda que as empresas se reorganizem, o valor da memória organizacional pode ser subestimado e, muitas vezes, as experiências passadas da empresa não são armazenadas, perdendo-se informações relevantes de sua história.

Davenport (2003) retrata que o conhecimento articula aspectos mais amplos, dizendo que o conhecimento é uma mistura fluida de experiência condensada, valores, informações construída e experimentada, a qual proporciona uma estrutura para validação e incorporação de novas práticas e construção de novos saberes.

Nas teorias são encontradas algumas tipologias que caracterizam o termo conhecimento, tais como: implícito, explícito sistemático, informal, codificável e não codificável. Entre eles, o mais comum e mais explorado é o tácito e explícito.

O conhecimento tácito é o embutido em nossas vidas, são fontes de conhecimento de difícil compartilhamento e possui a complexidade para sua transmissão. Iniciativa subjetiva configura esta categoria do conhecimento. Choo (2003) diz que apesar de não ser codificável, o conhecimento tácito pode ser ensinado e compartilhado. 0 conhecimento tácito pode ser aprendido por meio de exemplo e compartilhado por meio de formas ricas de discurso, que incluem o uso de analogias, metáforas ou modelos, e mediante o compartilhamento de histórias.

Diferentemente, o conhecimento explícito é visto pela literatura como conhecimento expressado por formas quantificadas de fácil comunicação e possível de compartilhar. Exemplos deste tipo de conhecimento são fórmulas científicas, manuais, entre outros.

Impossível tratar gestão do conhecimento sem evidenciar sua criação através de dados, informação e conhecimento. Segundo Lacombe e Heilborn (2003), os dados são registros de execução de processos que se consolidados, classificados, analisados e inseridos em determinado contexto geram informações. Essas, se manipuladas de maneira inteligente, resultam em conhecimento.

Para Teece (2000), há três objetivos fundamentais que caracterizam o movimento da gestão do conhecimento: (i) a criação de depósitos de conhecimento com informação externa: inteligência competitiva somado com práticas cabíveis na realidade da organização, e informação interna: relatórios de pesquisa, conhecimento interno informal como visões de banco de dados; (ii) o aprimoramento do acesso ao conhecimento e a reutilização deste por meio de ferramentas construídas com interfaces visando homem e máquina, e (iii) a valorização do ambiente organizacional para criar e armazenar os conhecimentos e experiências já presenciadas, de modo a serem exemplos.

Se o desenvolvimento do conhecimento de uma organização depende, em parte, das bases fornecidas pelo conhecimento anterior, as organizações que desejarem administrar seu conhecimento de modo que esteja disponível e acessível futuramente, deverão 
selecionar dentre muitos eventos, pessoas e processos, aqueles que devem ser retidos.

\section{Criação do conhecimento}

A criação do conhecimento organizacional tem sido considerada fundamental para a sobrevivência, pois pode armazenar conhecimentos embutidos em melhores práticas que agregam valor à empresa e assim podem disponibilizar forças para a sua sustentabilidade.

O autor Nonaka (1991) descreve que a criação do conhecimento organizacional é observada quando os mercados mudam, os pares das organizações se multiplicam, as tecnologias avançam e os produtos tornam-se defasados muito rapidamente. Afirmando neste sentido, Silva e Ayres (2008) destacam como um processo social, onde os atores relacionados com a organização criam novos conhecimentos a partir de suas manifestações.

Para que a empresa possa ter sucesso com a criação, indica-se que é preciso fazer a gestão de conhecimento disseminando amplamente por toda a organização e de fato realocar este conhecimento em novos processos, produtos e tecnologias para sua manutenção.

Nonaka e Takeuchi (1997) discorrem que a geração de conhecimento é um processo mutável que relaciona a interações entre diversos níveis da organização, direcionando as pessoas que amplificam, aprofundam e compartilham seu conhecimento. Nesta visão pode-se dizer que somente o armazenamento do conhecimento não retrata um processo completo de criação, pois se torna necessário a disseminação do mesmo.

0 processo de criação do conhecimento não pode ser capturado apenas como um modelo casual normativo, visto que os valores e ideais humanos são subjetivos e o conceito de verdade depende dos valores, ideais e contextos (NONAKA; TOYAMA, 2005).

Segundo Oliveira Junior (2001), seguindo a perspectiva de que as organizações possuem a capacidade de gerar e transferir o conhecimento no ambiente organizacional é preciso entender os mecanismos pelos quais o conhecimento pode ser criado e transferido. Apesar de inúmeras variáveis neste processo.

\section{Processo SECI}

Para que seja concreta a criação do conhecimento, se torna fundamental a interação entre o conhecimento tácito (subjetivo) e o explícito (mensurável). Este processo de criação do conhecimento organizacional é denominado de SECI (Socialização, Externalização, Combinação e Internalização), que ocorre mediante as interações dos conhecimentos, conforme já destacado (Figura 1).

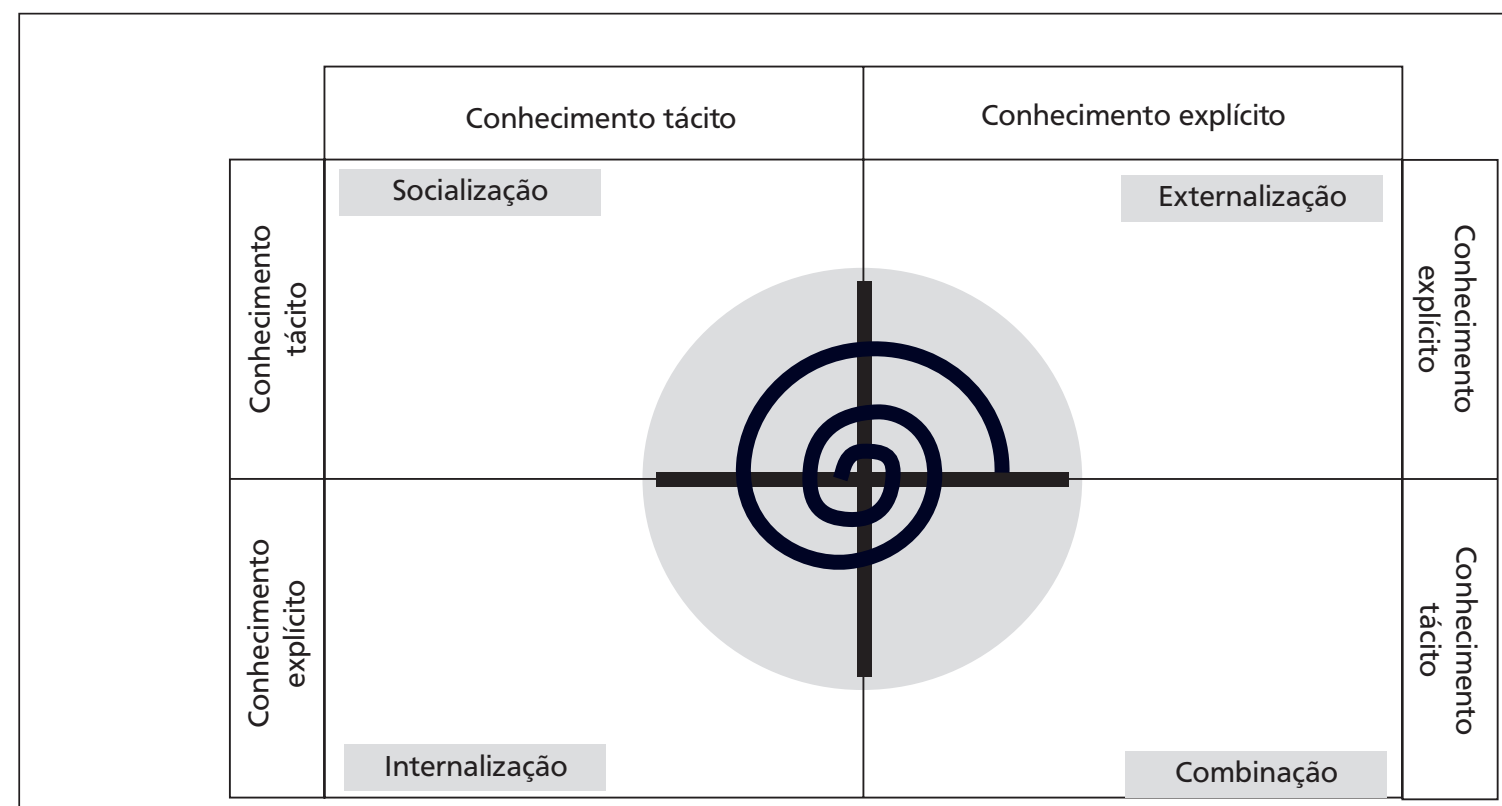

Figura 1 - Processo SECI

Fonte: Adaptado de NONAKA; TAKEUCHI, 1997, p. 80. 
Baseados neste modelo, os teóricos defendem os tipos de conversão do conhecimento: quando verificamos a socialização (de tácito para tácito); externalização (de conhecimento tácito para conhecimento explícito); combinação (de conhecimento explícito para o conhecimento explícito) e a internalização (de conhecimento explícito para o conhecimento tácito (CRUZ, 2007).

A fase de socialização, segundo Nonaka (1991), é definida como processo de compartilhamento de experiências e viabiliza a criação do conhecimento subjetivo. Para sintetizar, seria uma troca de conhecimento entre pessoas.

Na sequência temos a externalização, que concretiza a articulação do conhecimento tácito em explícito com práticas ou ações que são entendíveis ou até mesmo um registro sobre um conhecimento do indivíduo. Trata-se de tornar o subjetivo em algo quantificável. Para Nonaka (1991), esta conversão depende do uso sequencial de metáforas e analogias e modelos e até mesmo reflexões para construção do conceito de um novo modelo.
Já a fase de combinação, segundo Silva (2002), configura-se pelo agrupamento dos registros de conhecimentos. Nesta fase possivelmente será trocado e combinado o conhecimento explícito de forma sistemática (NONAKA; TAKEUCHI, 1997).

Sobre a internalização, Cruz (2007) escreve que nela ocorre a prática de aprender fazendo, através da verbalização, diagramação e modelos mentais. Importante destacar que quando a organização compartilha do novo o conhecimento pode passar a fazer parte da cultura organizacional. E a cada internalização concretizada o ciclo se reinicia, levando a aquisição de novas competências ou a criação de novos processos ou produtos.

Adicionam como fundamental que, para disseminar, desenvolver e incorporar o conhecimento, é necessário um contexto específico, que não requer estrutura necessariamente e sim um ambiente propício. Este cenário foi denominado por $b a$. Segundo os japoneses, o $b a$ é a chave para criação, compartilhamento e utilização dos conhecimentos armazenados (Figura 2).

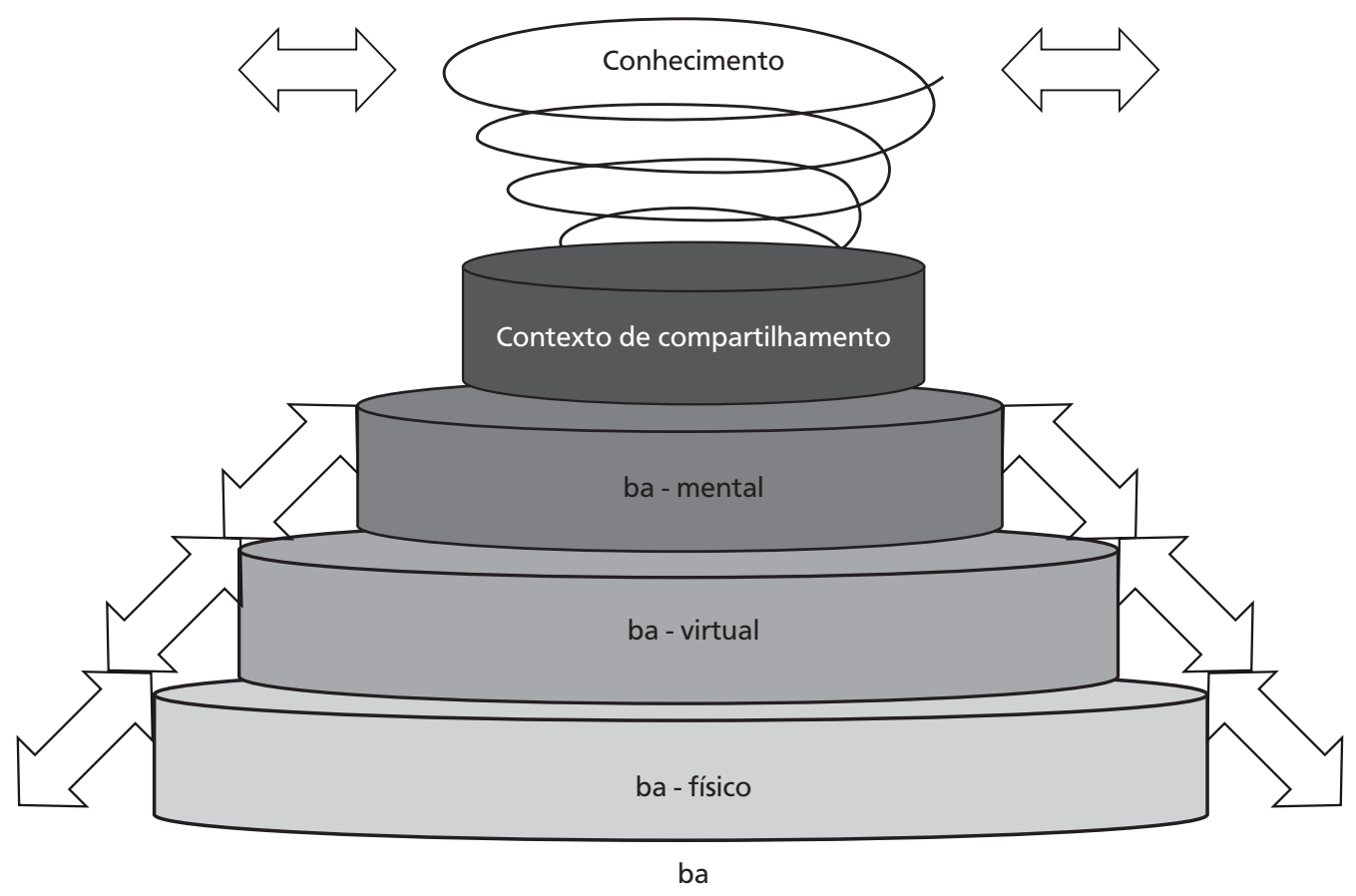

Contexto de individual

Figura 2 - Modelo conceitual do ba

Fonte: Adaptado de NONAKA; TAKEUCHI (1997). 
Quando se evidencia a articulação e prática do espiral, fica provável que há criação do conhecimento, deixa de ser algo esporádico e torna-se prática rotineira dentro do contexto organizacional. Segundo Nonaka e Toyama (2005), mediante o compartilhamento de contextos individuais, seja físico, mental, virtual ou existencial, todos eles promovem efetivamente os ciclos do espiral do conhecimento.

\section{Gestão estratégica com gestão do conhecimento}

$\mathrm{Na}$ atualidade, diversos mecanismos são usados para obter maiores indicativos positivos em uma organização, e apenas empresas no formato de conhecimento conseguem atribuir esse valor em suas operações.

Na execução do processo estratégico existe o encadeamento de processos de aprendizagem, sem que haja desmerecimento de vincular aprendizagem com estratégia, notadamente vinculado ao conhecimento já adquirido pela empresa (HAYASHI, 2009).

Existem muitos benefícios alcançados nas organizações ao adotarem uma gestão organizada e apoiada na gestão de conhecimento. Sem dúvida, oferece maior agilidade e capacidade de resposta no ambiente e aumenta significativamente a contribuição do capital intelectual para que as organizações se tornem mais competitivas e rentáveis no seu cenário de atuação.

Para conseguir alcançar uma gestão baseada em conhecimento, é preciso compreender seus processos dentro e fora da organização, e com isso é possível identificar seu conhecimento. Sveiby (1998) identifica o conhecimento na organização em três âmbitos:

a) conhecimento dos colaboradores: como eles conseguem criar ativos;

b) estrutura interna: patente, propriedade intelectual, estrutura, entre outros;

c) estrutura externa: aspectos que se relacionam com os processos internos em todos os sentidos.

Atualmente, as organizações têm reconhecido que o conhecimento é necessário para mantê-las competitivas no mercado e melhorar significativamente o seu desempenho, e as práticas de gestão do conhecimento podem oferecer apoio a essa necessidade organizacional.
Pode-se destacar que a gestão do conhecimento é um elemento forte para a contribuição da gestão estratégica da organização, principalmente se a cultura organizacional for baseada na modesta ideia de mente aberta. Alguns benefícios podem ser alcançados na sua indexação à gestão da organização, como geração de novos produtos, serviços e práticas de otimização, partilha de conhecimento individual-empresa, ou seja, não terá um conhecedor do novo, muitos terão este conhecimento, a socialização de tendência e dificuldade gerando novos desafios, assim como a transferência automática de conhecimento.

Segundo Stewart (1998), uma organização tradicional é um conjunto de ativos físicos, adquiridos por capitalistas responsáveis por sua manutenção e que contratam pessoas para operá-los. Uma empresa baseada em conhecimento se difere de muitas formas, pois não só os principais ativos são intangíveis. $\mathrm{Na}$ organização do conhecimento, portanto, o principal ativo é o capital intelectual que atende às demandas internas e externas da organização.

Não deixemos de lado a importância da cultura organizacional com mente aberta para que se torne tudo isso já descrito uma realidade. Dificilmente uma organização nos dias atuais não demanda uma cultura mais flexível devido à competitividade enfrentada. A cultura cumpre várias funções no seio de uma organização: define os limites, transmite um sentido de identidade a seus membros, facilita a criação de um comprometimento pessoal com algo mais amplo que os interesses egoístas do indivíduo, e estimula a estabilidade do sistema social.

Quanto à relação entre a estrutura organizacional e o processo de gestão do conhecimento, Stewart (1998) destaca que as estruturas hierárquicas transferem conhecimento verticalmente, através de uma cadeia de comando, mas inibem a transferência horizontal que deve atravessar as barreiras intraorganizacionais.

\section{Metodologia}

A análise sobre as práticas de gestão do conhecimento nas organizações não baseadas em conhecimento é um tema que não tem sido explorado nas literaturas. Ela pode ser caracterizada como uma pesquisa exploratória, pois realiza descrições categóricas da situação, objetivando descobrir as relações existentes entre os elementos que são próprios, e 
neste viés também explora um assunto pouco abordado, medindo características descritas nas questões de pesquisa (GIL, 2002).

A coleta de dados foi desempenhada in loco intencionalmente. Num primeiro momento foram convidadas, por e-mail, dez empresas de algumas cidades do Paraná. Dessas dez empresas escolhidas intencionalmente, três indústrias de grande porte aceitaram participar do estudo. Essas organizações estão situadas nas cidades de Pato Branco, Ponta Grossa e Curitiba.

Para a coleta de dados, a técnica adota foi a tecnologia de informação e comunicação, o que permitiu o envio de um questionário, por meio de correio eletrônico, utilizando o módulo de Google docs. Após o recebimento, foi agendada a visita e realizado o preenchimento junto ao gerente, via internet.

O questionário emprega a escala de Likert, contida no intervalo de 1 a 7 , em que 1 corresponde à alternativa discordo totalmente e 7 concordo plenamente, visando mensurar a percepção dos dirigentes em relação aos elementos da gestão estratégica do conhecimento. Esta escala descarta as respostas de resposta 3 e 4, nas quais há opiniões parciais que não efetivam sua resposta.

0 instrumento, adaptado pelos autores, teve como fonte as questões utilizadas por Cruz (2007), que investigou empresas contidas em parques tecnológicos, o que garantiu a análise completa de sua dissertação de mestrado em engenharia e está permitindo o diagnóstico de outro cenário, onde deve garantir a validação notadamente sobre outro cenário que será exposto.

O tempo utilizado para a pesquisa foi entre os meses de janeiro a março de 2011, e as cidades já mencionadas, pertencem ao estado do Paraná. Visto o interesse em pesquisar empresas de grande porte por evidenciarem uma gestão estratégica mais consolidada que as de menor porte.

\section{Análise e discussão dos resultados}

Na perspectiva de alcançar o resultado de socialização do conhecimento nas organizações, foram utilizadas as perguntas da Quadro 1, que por tratar de socialização tem como base o levantamento de compartilhamento de dúvidas, novas propostas, transferência de conhecimento e atualização profissional.

Na prática de socialização do conhecimento, as organizações demonstram um resultado muito favorável. 0 resultado dessas indústrias garante, por parte dos funcionários, uma boa relação entre a gestão estratégica e o colaborador colaborando com as práticas de gestão do conhecimento (Gráfico 1).

A externalização, por sua vez, é uma prática vista resumidamente por questões como trabalho em conjunto e valorização de iniciativa. No Quadro 2, as questões pertinentes ao levantamento de externalização do conhecimento.

Podemos perceber no Gráfico 2 as seguinte questões sobre a externalização do conhecimento esboçando um índice relativamente baixo, principalmente na questão de repasse do conhecimento para outros colaboradores. Com isso percebemos um impacto negativo sobre treinamentos por pessoas internas.

Como evidenciado anteriormente sobre a externalização do conhecimento como sendo uma das dificuldades encontradas nessas indústrias, no resultado sobre a combinação do conhecimento (Gráfico 3), que seria distribuir um conhecimento após a criação do mesmo, identificamos que existe um percentual baixo neste indicativo.

Quadro 1 - Questões destinadas ao diagnóstico de socialização do conhecimento

\section{Questões}

1 - Quando um funcionário está em dúvida sobre determinada atividade de trabalho, uma de suas primeiras ações é recorrer a um colega de trabalho.

2 - A empresa contrata cursos e treinamentos para seus funcionários, sempre que surge um novo projeto no qual o funcionário deverá desempenhar uma atividade diferente daquela até então exercida.

3 - Após aprimorarem seus conhecimentos em seus cursos e treinamentos, os funcionários interagem sobre os conceitos aprendidos.

4 - Os funcionários estão sempre a par do conhecimento da empresa e de suas necessidades de qualificação, buscando se especializar mesmo quando não há qualquer subsídio da empresa.

Fonte: Adaptado de CRUZ, 2007. 
Quadro 2 - Questões destinadas ao diagnóstico de externalização do conhecimento

\section{Questões}

1 - Os projetos de trabalhos são realizados em sua maioria por equipes que executam suas atividades e análises, através de interações conjuntas.

2 - É comum entre os funcionários o uso de metáforas e analogias para explicar ideias e atividades.

3 - Novas ideias são valorizadas. Há grupos de discussão de ideias que a princípio pareçam irrelevantes.

Fonte: Adaptado de CRUZ, 2007.

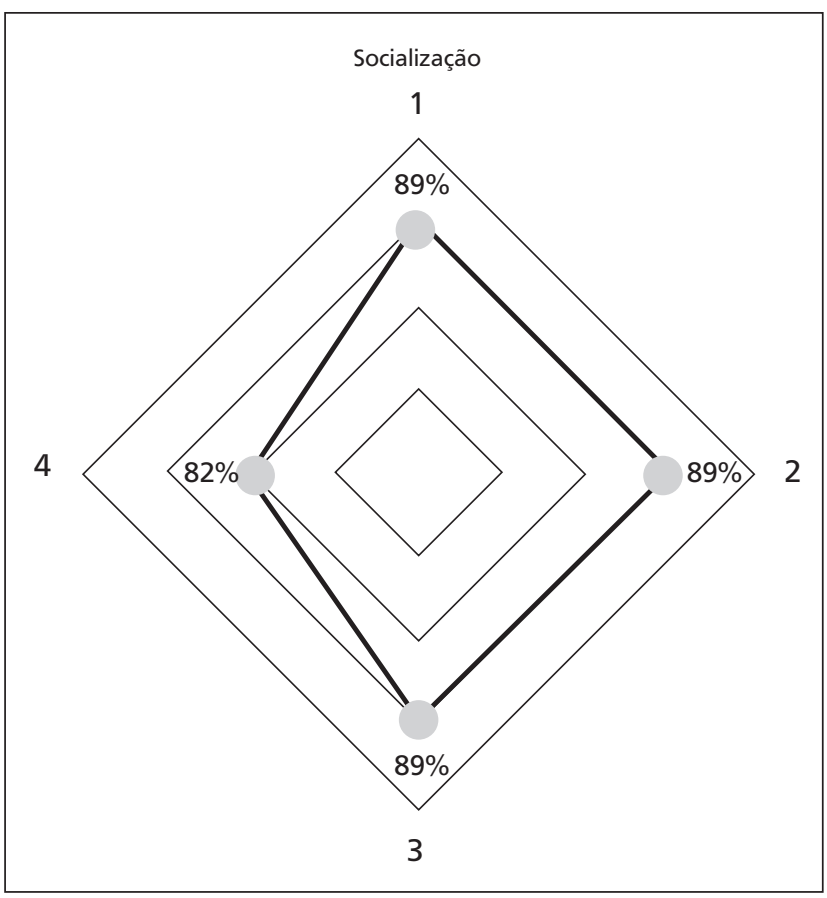

Gráfico 1 - Gráfico de socialização do conhecimento Fonte: Dados da pesquisa.

A seguir, o Quadro 3 com as questões que objetivam identificar a combinação do conhecimento dentro das indústrias pesquisadas.

Para diagnóstico de internalização do conhecimento (Gráfico 4), foram utilizadas as questões da Quadro 4, onde as questões estão mais focadas em adesão do conhecimento, com atividades que deslocam os colaboradores a ter uma interação mais positiva dentro do contexto organizacional.

Nesta prática foram diagnosticados percentuais mais preocupantes, devido a muitas organizações estarem em dúvida a respeito de reter o conhecimento que existe dentro de seu contexto.

A contribuição efetiva dos colaboradores com iniciativa de empreendedorismo torna a organização cada

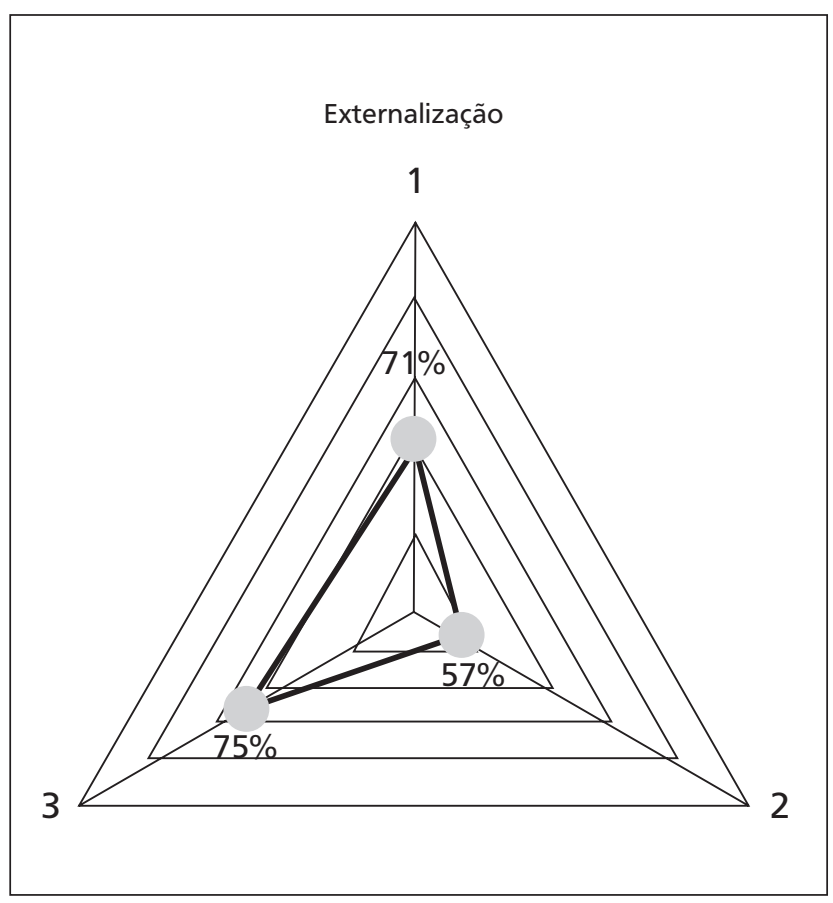

Gráfico 2 - Gráfico de externalização do conhecimento baseado em práticas

Fonte: Dados da pesquisa.

vez mais competitiva, isso é meta para muitas organizações que pretendem ser sustentáveis em seu meio.

Buscar um diagnóstico sobre estas atividades também faz parte deste contexto, conforme mostra o Quadro 5 as perguntas relacionadas com relação de iniciativa buscando a contribuição individual para sua organização. Prática que é possível estimular através de comportamentos advindos da cultura organizacional. Os resultados alcançados ilustram uma cultura (Gráfico 5) divergente no que se prega com a gestão do conhecimento, principalmente nas organizações do conhecimento. A cultura organizacional contempla a estratégia da organização que posteriormente abastece todas as subáreas do ambiente organizacional. Quando tratamos de recursos humanos, 
possivelmente as práticas exercidas são reflexos de interesses maiores.

No Quadro 6 as perguntas foram destinadas ao levantamento de práticas na rotina dos recursos humanos que se relacionam com a gestão do conhecimento, rotinas de reconhecimento e mérito aplicado principalmente a processos de encarreiramento. Também o recrutamento de pessoas foi foco por estar agregando conhecimento à organização, assim como a recompensa estimulada pelas melhores práticas na organização.

Quadro 3 - Questões destinadas ao diagnóstico de combinação do conhecimento

\section{Questões}

1 - Na empresa há grupos de discussão que se relacionam por meio de ambientes virtuais, tais como: fóruns virtuais e grupos de e-mails.

2 - O(s) banco(s) de dados da empresa é (são) intensamente acessado(s), tanto para armazenar como para fornecer dados/informações a todos na empresa.

3 - A empresa prevê sistemas integrados que incentivam diálogos por meio de intranet e internet, tais como: e-mails, MSN, CRM.

4 - A empresa exige que, após a conclusão de projetos e atividades, os funcionários redijam relatórios sobre os mesmos.

Fonte: Adaptado de CRUZ, 2007.

Quadro 4 - Questões destinadas ao diagnóstico de Internalização do conhecimento

\section{Questões}

1 - Os ambientes virtuais de comunicação (intranet, internet) são utilizados mais como veículos de comunicação entre dois indivíduos ao invés de ser entre grupos.

2 - Todos os funcionários estão aptos a dizer, se questionados, qual a meta e a missão da empresa.

3 - Os funcionários, em sua maioria, apresentam mais know how técnico, isto é, são mais especialistas do que generalistas.

4 - Quando um funcionário começa a realizar uma nova atividade que ele nunca exerceu, ele tenta desempenhá-la, primeiramente, por meio da prática, isto é, aprender fazendo.

Fonte: Adaptado de CRUZ, 2007.

Quadro 5 - Questões destinadas ao diagnóstico de cultura organizacional

\section{Questões}

1 - Os funcionários têm consciência de que se contribuírem com o alcance da meta da empresa, por exemplo, criando um produto/serviço inovador, eles serão reconhecidos (valorizados).

2 - A experimentação é estimulada. Há liberdade para tentar e falhar.

3 - As pessoas estão preocupadas com toda a organização e não apenas com sua área de trabalho, buscando soluções conjuntas.

Fonte: Adaptado de CRUZ, 2007.

Quadro 6 - Questões destinadas ao levantamento de práticas dos recursos humanos

(continua)

\section{Questões}

1 - Os cursos, especializações e títulos obtidos pelos funcionários são valorizados.

2 - Os recém-contratados, antes de iniciarem suas atividades, são treinados pelos funcionários mais antigos da empresa. 
Quadro 6 - Questões destinadas ao levantamento de práticas dos recursos humanos

\section{Questões}

3 - Existem esquemas de participação nos lucros, premiação e recompensas por resultados e contribuições.

4 - Na contratação busca-se a diversidade (personalidades, experiências, cultura, etc.) em detrimento do know how técnico.

Fonte: Adaptado de CRUZ, 2007.

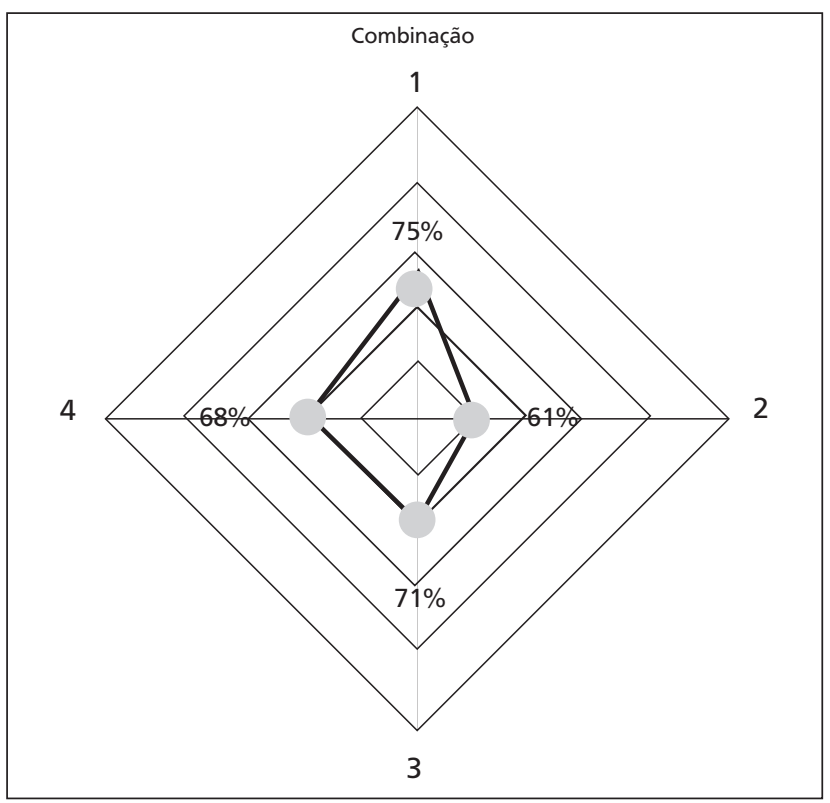

Gráfico 3 - Gráfico de combinação do conhecimento baseado em práticas

Fonte: Dados da pesquisa.

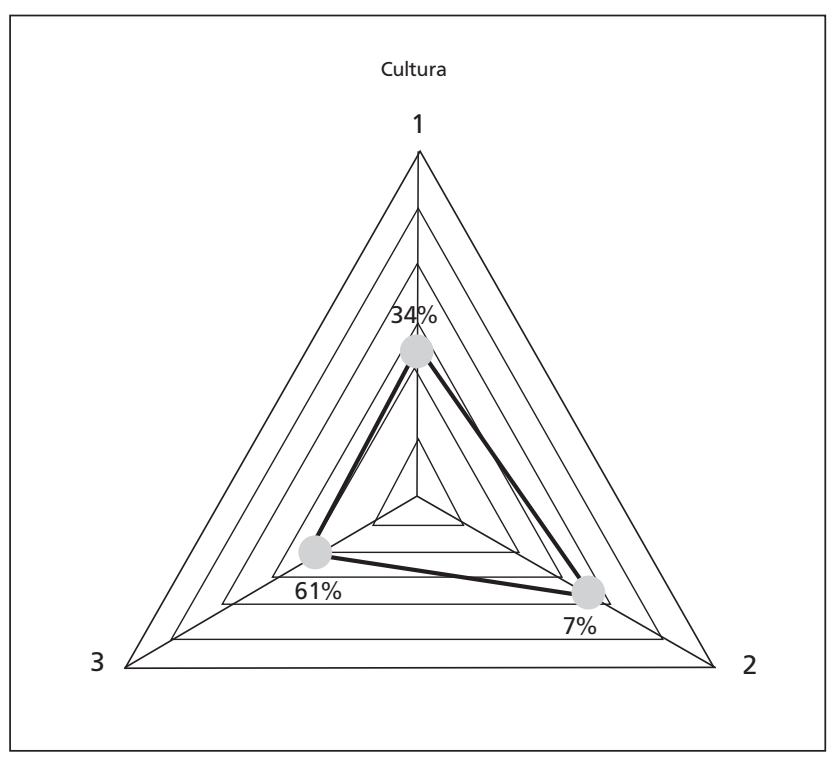

Gráfico 5 - Gráfico de cultura organizacional baseado em práticas

Fonte: Dados da pesquisa.

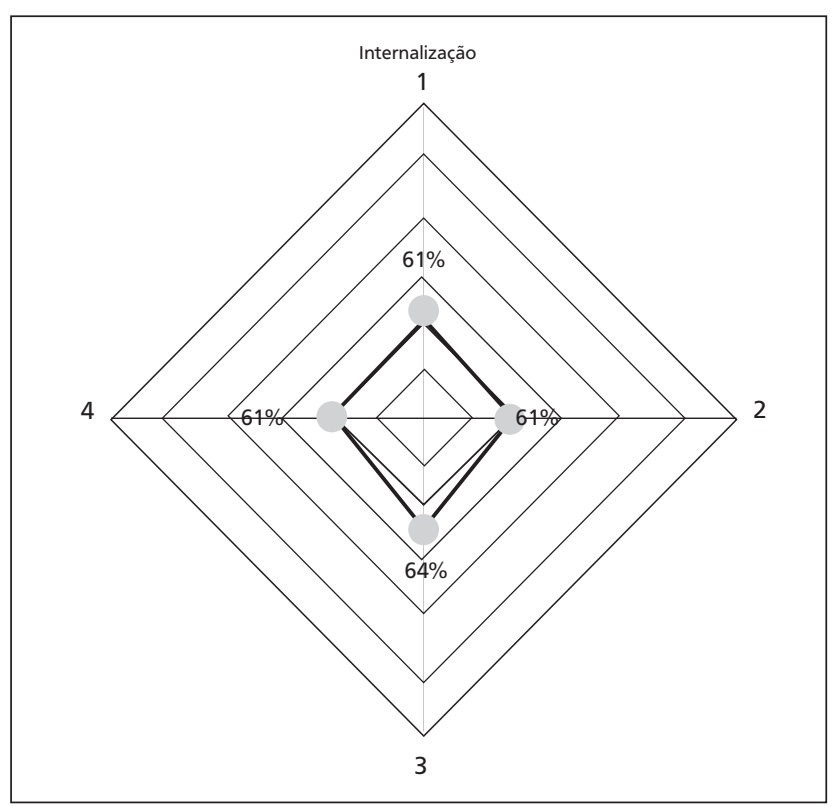

Gráfico 4 - Gráfico de internalização do conhecimento baseado em práticas

Fonte: Dados da pesquisa.

No Gráfico 6 os resultados demonstram um positivo resultado que assume o papel de gerir o conhecimento pelo fato de que as organizações têm atendido à exigência do mercado atendendo às necessidades dos recursos humanos que geram significativamente o valor agregado para a empresa.

Para tratar da tecnologia da informação nas organizações percebendo o grande impacto nas práticas de gestão do conhecimento (Gráfico 7), foram destinadas três questões que englobam vários aspectos de armazenamento, compartilhamento e utilização do conhecimento gerado. Com esse objetivo foram focados trabalho em rede, investimento em infraestrutura e compartilhamento de banco de dados.

Como vivemos no meio da tecnologia as organizações tendem a se interessar em trabalhar cada vez mais apoiado a essa tecnologia, caso contrário, não seria possível obter um resultado favorável e continuarem organizações atualizadas. 


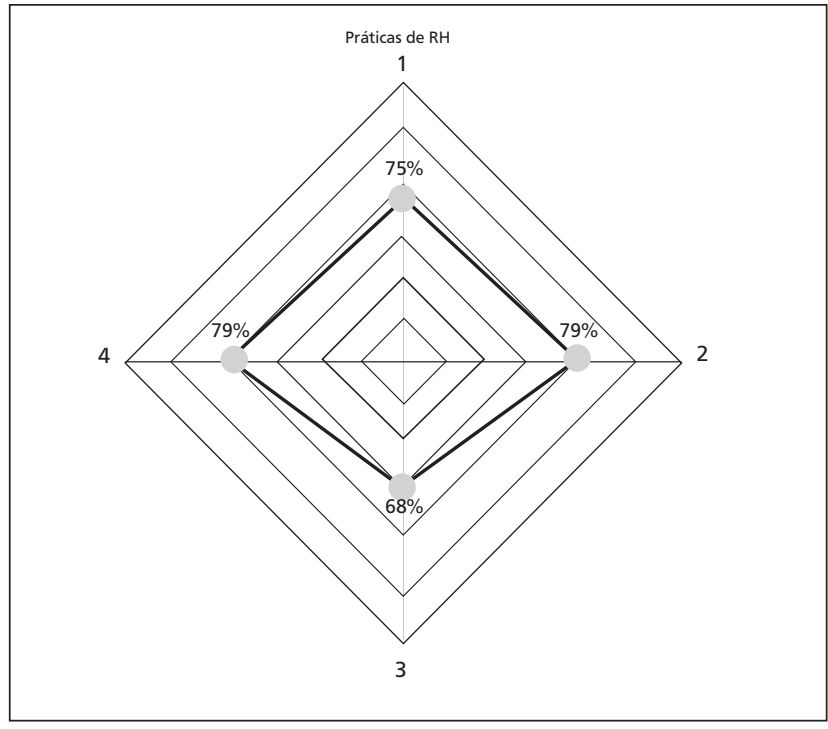

Gráfico 6 - Gráfico de práticas de RH - recursos humanos Fonte: Dados da pesquisa.

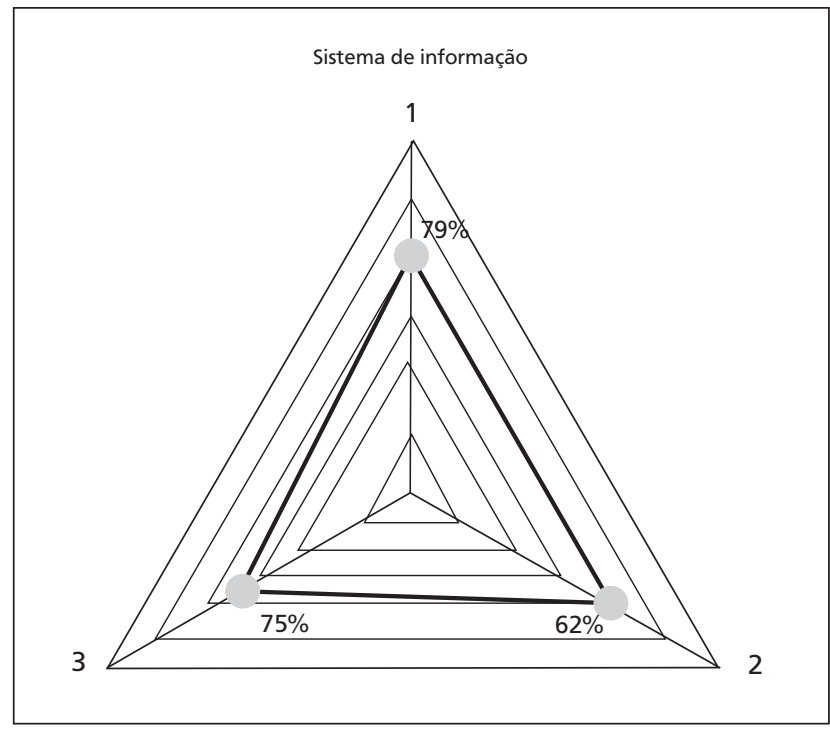

Gráfico 7 - Gráfico de práticas de GC utilizando sistemas de informação

Fonte: Dados da pesquisa.

Quadro 7 - Questões destinadas ao diagnóstico de cultura organizacional

\begin{tabular}{l} 
Questões \\
\hline 1 - Todos os sistemas de informação estão integrados, assim é possível que qualquer área da empresa tenha acesso ao conteúdo \\
das demais, via intranet. \\
2 - Um dos maiores investimentos realizados pela empresa anualmente dedica-se aos sistemas de informação. \\
3 - A comunicação, por meio das redes de comunicação, é eficiente em todos os sentidos (de cima para baixo, de baixo para cima e \\
entre diferentes áreas).
\end{tabular}

Fonte: Adaptado de CRUZ, 2007.

Importante destacar também que os sistemas de informação têm colocado o cenário organizacional em uma comunicação ágil, mas ao mesmo tempo têm influenciado a quantidade do contato humano no dia a dia do trabalhador, o que causa impacto nas outras práticas do conhecimento.

\section{Considerações finais}

A pesquisa descrita foi desenvolvida com objetivo de demonstrar as práticas de gestão do conhecimento relacionadas aos processos advindos da gestão estratégica da organização em três indústrias do estado do Paraná. Neste contexto, aplicou se uma análise quantitativa dos dados coletados.
Assim, a partir da aplicação da metodologia escolhida, pode-se concluir que existem algumas práticas realmente relacionadas com as rotinas efetivamente exercidas no processo diário, entretanto identificamos que as organizações deixam de vincular em seu processo de gestão estratégica. São elas: (i) Explicação de ideias e atividades; (ii) Acesso à informação construída pela organização; (iii) Colaboradores em registrar relatórios sobre projetos construídos; (iv) Internalização do conhecimento através de estímulo da empresa para com o funcionário; (v) Comprometimento dos funcionários com a empresa e vice-versa no que se diz respeito à valorização e reconhecimento.

A prática de gestão do conhecimento inserida no processo de gestão estratégica pode influenciar diretamente com os resultados da entidade, por isso 
podemos criteriosamente destacar que se empresas como essas de grande porte não atribuem o conhecimento vinculado com a estratégia, possivelmente deverão rever seus conceitos para futuramente não aumentar seu custo e, assim, alcançar sua sustentabilidade.

Após o alinhamento estratégico junto às práticas de gestão do conhecimento, podemos alcançar a recompensa, que pode vir através do aumento de força de trabalho e a qualificação do capital intelectual, tornando a organização cada vez mais competitiva.

A partir deste estudo conclui-se que as organizações pesquisadas apontam um índice positivo, mas podem melhorar com a inserção de outras práticas destacadas no estudo, o que poderá resultar em melhores condições para que alcancem seus objetivos.

Por fim, sugerimos para estudos futuros as seguintes considerações: fazer um diagnóstico sobre atividades relacionadas com estes aspectos levantados anteriormente para saber quais as causas que acabam inibindo a sua utilização e discutir sobre ferramentas para utilizar no processo de planejamento estratégico que possam levar em consideração a gestão do conhecimento.

\section{Referências}

CHOO, C. W. A organização do conhecimento: como as organizações usam a informação para criar significado, construir conhecimento e tomar decisões. São Paulo: SENAC, 2003.

CRUZ, C. A. Gestão estratégica do conhecimento: estudo exploratório em empresas instaladas nos parques tecnológicos do Estado de São Paulo. 2007. 164 f. Dissertação (Mestrado em Engenharia de Produção) - Universidade de São Paulo, São Carlos, 2007.

DAVENPORT, T. H.; PRUSAK, P. Conhecimento empresarial: como as organizações gerenciam o seu capital intelectual. Tradução de Lenke Peres. Rio de Janeiro: Elsevier, 2003.

GIL, A. C. Como elaborar projetos de pesquisa. 4. ed. São Paulo: Atlas, 2002.

HAYASHI, J. P. Múltiplas contingências e o processo de adaptação estratégica. Revista Brasileira de Estratégia, v. 2, n. 1, p. 75-81, 2009. Disponível em: <http://www2.pucpr.br/reol/index.php/REBRAE?dd1=4504\&dd99=view $>$. Acesso em: 3 mar. 2011.

LACOMBE, F.; HEILBORN, G. Administração: princípios e tendências. São Paulo: Saraiva, 2003.
NONAKA, I. The knowledge-creating company. Harvard Business Review, v. 69, p. 96-104, 1991.

NONAKA, I.; TAKEUCHI, H. Criação de conhecimento na empresa: como as empresas japonesas geram a dinâmica da inovação. 13. ed. Rio de Janeiro: Elsevier, 1997.

NONAKA, I.; TOYAMA, R. The theory of the knowledge-creation firm: subjectivity, objetctivity and synthesys. Industrial and Corporate Change, v. 14, n. 3, p. 419-436, 2005.

OLIVEIRA JUNIOR, M. M. Competências essenciais e conhecimento na empresa. In: FLEURY, M. T. L.; OLIVEIRA JUNIOR, M. M. (Org.). Gestão estratégica do conhecimento. São Paulo: Atlas, 2001.

PEREIRA, H. J. Proposição de um modelo organizacional baseado no conhecimento: um estudo de caso em empresa pública. In: INTERNATIONAL CONFERENCE OF THE IBERO-AMERICAN ACADEMY OF MANAGEMENT, 3., 2003, São Paulo. Anais... São Paulo: IBERO-AMERICAN, 2003.

SANTOS, I. C.; NETO, J. A. Gestão do conhecimento em indústria de alta tecnologia. Produção, v. 18, n. 3, p. 569-582, 2008. Disponível em: <http://www.scielo.br/pdf/prod/

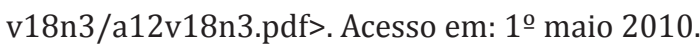

SILVA, S. L. Proposição de um modelo para caracterização das conversões do conhecimento no processo de desenvolvimento de produtos. 2002. $231 \mathrm{f}$. Tese (Doutorado em Mecânica) - Universidade de São Paulo, São Paulo, 2002.

SILVA, R. S. da; AYRES, R. M. S. de M. A identificação das fontes de formação das capacidades estratégicas da operação. Revista Gestão Organizacional, v. 6, n. 1, p. 73-89, 2008.

STEWART, T. A. Capital intelectual: a nova vantagem competitiva das empresas. Rio de Janeiro: Campus, 1998.

SVEIBY, K. E. A nova riqueza das organizações: gerenciando e avaliando patrimônios de conhecimento. 3. ed. Rio de Janeiro: Campus, 1998.

TEECE, D. J. Strategies for managing knowledge assets: the role of firm structure and industrial context. Long Range Planning, v. 33, p. 35-54, 2000.

Recebido: 30/07/2011

Received: 07/30/2011

Aprovado: 29/08/2011

Approved: 08/29/2011 